\title{
FROM THE EDITOR. ....
}

Though Maslow's "Hierarchy of Needs" does not specifically mention it, transportation has now become a basic human requirement. As with any other need fulfillment, transportation has a price, in this case a rather exorbitant price, fixed on to it. Over the demand for commuting to work necessitated by an economy based on activity centers, social perceptions too have created a further pressure on private rather than public transport as reflected by the ratio of public to private vehicles plying the roads.

This scenario in turn creates a severe strain on the economy as increased numbers of individual transportation units consume more fossil fuels, contribute more in environmental degradation, and create more lost productive time due to congestion, per capita per kilometer. Further at micro level, expenditure on private transport in the form of vehicles such as cars easily exceeds even the monthly budget on food, for a middle-income family if capital, maintenance and fuel costs are aggregated.

Solution to this obviously is enhanced public transportation in the mass scale. The answer, which had been lying with us all this time, neglected if not forgotten, is the railway. Technical factors such as minimized rolling resistance, higher capacity per unit of transit, possibility of better coordination, etc., make it the best option, as portrayed by adoption in developed countries.

It is heartening to see that we too are at last going the right way, in developing the rail transport. As seen on the cover page a second railway bridge is being erected over Kalu Ganga, to enhance the capacity of the coastal line.

Eng. (Dr.) T. M. Pallewatta, PEng (SL), C.Eng, FIE(SL)

Editor 